\title{
BACTERIOLOGICAL STUDY OF DEEP NECK SPACE ABSCESS
}

\author{
Sheila Raman Kutty1, Balakrishnan², Rajan Cayyappilly³, Swathy Jaya Chandran ${ }^{4}$ \\ ${ }^{1}$ Associate Professor, Department of ENT, Academy of Medical Sciences, Pariyaram, Kannur, Kerala. \\ 2 Professor, Department of ENT, Academy of Medical Sciences, Pariyaram, Kannur, Kerala. \\ 3 Professor, Department of Microbiology, Academy of Medical Sciences, Pariyaram, Kannur, Kerala. \\ ${ }^{4}$ Resident, Department of ENT, Academy of Medical Sciences, Pariyaram, Kannur, Kerala.
}

ABSTRACT
BACKGROUND
The complexity of the deep location of these neck spaces make diagnosis and treatment of the infections difficult. Deep neck space
infections affect fascial compartments of the head and neck and their contents. Compared with infections elsewhere in the body,
deep neck infections pose complicated problems due to numerous portals of entry of infection and proximity to vital structures.
The objective of the study is to study the bacteriology, antibiotic sensitivity and management options of deep neck space
infections.

\section{MATERIALS AND METHODS}

50 cases of deep neck infections admitted in Academy of Medical Sciences, Pariyaram, Kannur, India between February 2014 and August 2015 with deep neck space infections were included in the study. Pus was sent for culture and sensitivity analysis. Microbiological assessments were analysed.

\section{RESULTS}

The most common organism isolated was Staphylococcus aureus (24\%) followed by Beta haemolytic streptococci (16\%). Most of the organisms isolated were sensitive to cephalosporins, gentamicin and ciprofloxacin; 2 isolates among Staphylococci (16.6\%) were Methicillin resistant (MRSA). MRSA should be considered as a potential pathogen in deep neck space abscesses. The main morbidity was airway obstruction in 2 (4\%) patients and required tracheostomy.

\section{CONCLUSION}

There is an increase in the isolation of methicillin resistant staphylococcus aureus (MRSA) in cases of deep neck infections. Empirical antibiotic treatments must cover gram positive, gram negative and anaerobic pathogens. Early surgical intervention can reduce the complications.

\section{KEYWORDS}

Deep Neck Infection, Methicillin Resistant Staphylococcus aureus.

HOW TO CITE THIS ARTICLE: Kutty SR, Balakrishnan, Cayyappilly R, et al. Bacteriological study of deep neck space abscess. J. Evolution Med. Dent. Sci. 2017;6(73):5263-5266, DOI: 10.14260/Jemds/2017/1142

\section{BACKGROUND \\ The complexity of the deep location of these neck spaces make diagnosis and treatment of the infections difficult. Deep neck space infections affect fascial compartments of the head and neck and their contents. Compared with infections elsewhere in the body, deep neck infections pose complicated problems due to numerous portals of entry of infection and proximity to vital structures. Although, the incidence of deep neck space infections was much higher in the pre-antibiotic era, it still continues to be a health problem where it causes significant morbidity and mortality. \\ The increasing prevalence of patients with immuno- deficiency or prior antibiotic treatment may result in unusual clinical presentations and pathogens, making the clinical diagnosis and treatment difficult.}

Financial or Other, Competing Interest: None.

Submission 04-08-2017, Peer Review 29-08-2017,

Acceptance 02-09-2017, Published 11-09-2017.

Corresponding Author:

Dr. Sheila Raman Kutty,

Department of ENT,

Academy of Medical Sciences,

Pariyaram, Kannur, Kerala.

E-mail: sheelaent@yahoo.com

DOI: $10.14260 /$ jemds $/ 2017 / 1142$

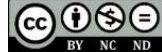

Failure to recognise deep space infections early may be due to an altered clinical picture resulting from inappropriate use of antibiotic, increasing prevalence of the patients with immunodeficiency and changes in the causes of deep neck space infections and its bacteriology. Before the widespread use of antibiotics, majority of the neck space infections originated in the pharynx and the tonsils. Since the advent of antibiotics, these oropharyngeal infections are no longer a significant aetiology. Dental infections and regional trauma are now common causes of deep neck space infections.

The microbiology of deep neck space infections usually reveals mixed aerobic and anaerobic organisms often with a predominance of oral flora. Both gram positive and gram negative organisms may be cultured. Group A beta haemolytic streptococci species, alpha haemolytic streptococcal species, staphylococcus, Fusobacterium nucleatum, bacteroides, peptostreptococci and Neisseria species are often found together in combination.(1)

Other important considerations include patients who are on chemotherapy or on immunosuppressant drugs for transplantation. These patients may have an increased frequency of deep neck space infections with atypical organisms and they may have more frequent complications. ${ }^{(2)}$

\section{MATERIALS AND METHODS}

A hospital-based prospective study was conducted in ENT 
OPD at Academy of Medical Sciences, Pariyaram, Kannur, Kerala, India between February 2014 and August 2015. A total no. of 50 patients were studied of both sexes and in all age groups. These patients attended ENT OPD with clinical and radiological evidence of deep neck space infections. Written informed consent for the study was obtained from the patients. Ethical committee clearance was obtained for the study.

Inclusion criteria included patients with complaints of throat pain, neck swelling, trismus, dysphagia, odynophagia, breathing difficulty, change in voice and foreign body sensation in the throat. Exclusion criteria included superficial skin abscesses, abscesses due to infections of the external neck wounds (surgical or traumatic) and abscesses related to fractures were excluded.

Study tools included a complete ENT, head and neck examination, Radiological examination which included x-ray neck lateral view, Ultrasound Neck and CECT, Pus culture and sensitivity tests. A detailed history, general and clinical examination was done including local examination of the swelling. Routine blood investigations were done.

Only clinically and radiologically confirmed cases of deep neck space infections of all age groups and both sexes were included in the study. Needle aspiration or incision and drainage was done at the earliest stage in majority of the patients. Pus was sent for culture and sensitivity analysis.

All data was entered into MS-EXCEL, then SPSS (Statistical package for social sciences) Version 13 was used for analysis of the data. The data thus obtained was analysed statistically and presented in the form of tables, figures and diagrams wherever necessary. Data collected was analysed statistically using descriptive statistical methods like frequencies and percentage. Results were presented in the form of both tables and graphs.

\section{RESULTS}

The study group included 50 patients with deep neck space infections. The culture was sterile in 15 (30\%) patients. Among the cases, the most common organism isolated was staphylococcus aureus (24\%) followed by Beta haemolytic streptococci $(16 \%)$. Most of the organisms isolated were sensitive to cephalosporins, gentamicin and ciprofloxacin; 2 isolates among Staphylococci (16.6\%) were Methicillin resistant (MRSA). MRSA should be considered as a potential pathogen in deep neck space abscesses. A high index of suspicion is needed as well as aggressive treatment including incision and drainage along with culture directed medical therapy.

Antibiotic coverage should include gram negative, gram positive and anaerobic organisms. A combination of third generation cephalosporins and metronidazole are good as empiric antibiotic coverage. MRSA shows resistance to most of the cephalosporins and routine antibiotics, while it responds well to Vancomycin and Linezolid. Our data also suggests that MRSA infections are on the rise and due consideration should be given to it.

Early surgical intervention was the mainstay of treatment. Empirical antibiotic therapy with cephalosporins and metronidazole was used.

Two patients developed airway obstruction and required tracheostomy and survived with intensive care monitoring.

\begin{tabular}{|c|c|c|}
\hline Organism Isolated & No. of Patients & Percentage \\
\hline Staphylococcus aureus & 12 & 24 \\
\hline$\beta$-haemolytic streptococci & 8 & 16 \\
\hline$\alpha$-haemolytic streptococci & 5 & 4 \\
\hline Pseudomonas & 2 & 6 \\
\hline Klebsiella & 3 & 30 \\
\hline No growth & 15 & \\
\hline \multicolumn{2}{|c|}{ Table 1. Bacteriology }
\end{tabular}

\begin{tabular}{|c|c|c|c|c|c|c|c|c|c|c|c|}
\hline 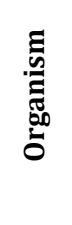 & z & 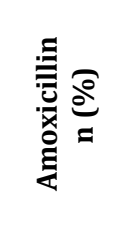 & 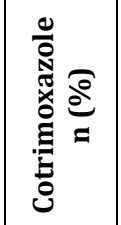 & 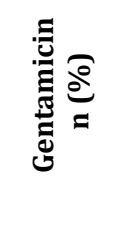 & 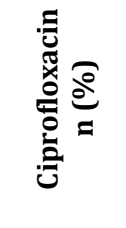 & 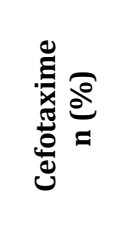 & 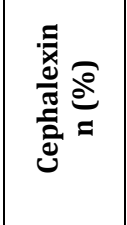 & 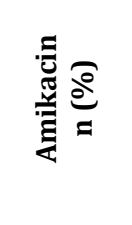 & 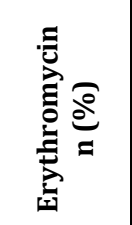 & 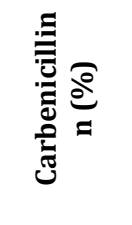 & 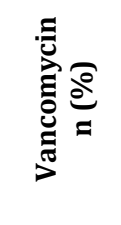 \\
\hline SA & $\begin{array}{c}12 \\
(100) \\
\% \% \% \\
(100 \% \\
(100) \\
\end{array}$ & $\begin{array}{c}6 \\
(50 \%)\end{array}$ & $\left|\begin{array}{c}4 \\
(33.3 \%)\end{array}\right|$ & $\begin{array}{c}9 \\
(75 \%)\end{array}$ & $\begin{array}{c}7 \\
(58.3 \%)\end{array}$ & $\begin{array}{c}7 \\
(58.3 \%)\end{array}$ & $\begin{array}{c}7 \\
(58.3 \%) \\
(100)\end{array}$ & $\begin{array}{c}5 \\
(41.6 \%)\end{array}$ & - & $\begin{array}{c}4 \\
(33.3 \%)\end{array}$ & $\begin{array}{c}12 \\
(100 \%)\end{array}$ \\
\hline$\beta \mathrm{HS}$ & $\begin{array}{c}8 \\
(100)\end{array}$ & $\begin{array}{c}1 \\
(12.5 \%) \\
(28.6)\end{array}$ & $\begin{array}{c}0 \\
(0 \%) \\
(57.1) \\
\end{array}$ & $\begin{array}{c}7 \\
(87.5 \%)\end{array}$ & $\begin{array}{c}8 \\
(100 \%) \\
(85.7)\end{array}$ & $\begin{array}{c}4 \\
(50 \%)\end{array}$ & $\begin{array}{c}8 \\
(100 \%) \\
(71.4)\end{array}$ & $\begin{array}{c}4 \\
(50 \%) \\
(71.4)\end{array}$ & - & $\begin{array}{c}4 \\
(50 \%)\end{array}$ & $\begin{array}{c}8 \\
(100 \%)\end{array}$ \\
\hline$\alpha \mathrm{HS}$ & $\begin{array}{c}5 \\
(100 \%)\end{array}$ & $\begin{array}{c}5 \\
(100 \%)\end{array}$ & $\begin{array}{c}0 \\
(0 \%)\end{array}$ & $\begin{array}{c}5 \\
(100 \%)\end{array}$ & $\begin{array}{c}2 \\
(40 \%) \\
(100)\end{array}$ & $\begin{array}{c}5 \\
(100 \%)\end{array}$ & \begin{tabular}{|c|}
5 \\
$(100 \%)$ \\
$(100)$ \\
\end{tabular} & $\begin{array}{c}5 \\
(100 \%)\end{array}$ & - & $\begin{array}{c}2 \\
(40 \%)\end{array}$ & $\begin{array}{c}5 \\
(100 \%)\end{array}$ \\
\hline$P$ & $\begin{array}{c}2 \\
(100)\end{array}$ & $\begin{array}{c}0 \\
(0 \%) \\
(33.3) \\
\end{array}$ & $\begin{array}{c}1 \\
(50 \%)\end{array}$ & - & $\begin{array}{c}2 \\
(100 \%) \\
(100) \\
\end{array}$ & - & \begin{tabular}{|c|}
2 \\
$(100 \%)$ \\
$(100)$ \\
\end{tabular} & $\begin{array}{c}2 \\
(100) \\
(66.7) \\
\end{array}$ & $\begin{array}{c}2 \\
(100 \%)\end{array}$ & $\begin{array}{c}2 \\
(100 \%)\end{array}$ & - \\
\hline K & $\begin{array}{c}3 \\
(100)\end{array}$ & $\begin{array}{c}2 \\
(66.6 \%)\end{array}$ & $\mid \begin{array}{c}2 \\
(66.6 \%)\end{array}$ & - & $\begin{array}{c}2 \\
(66.6 \%) \\
(100) \\
\end{array}$ & - & \begin{tabular}{|c|}
2 \\
$(66.6 \%)$ \\
$(66.7)$ \\
\end{tabular} & $\begin{array}{c}2 \\
(66.6)\end{array}$ & $\begin{array}{c}2 \\
(66.6 \%)\end{array}$ & $\begin{array}{c}0 \\
(0 \%)\end{array}$ & - \\
\hline
\end{tabular}




\begin{tabular}{|c|c|c|}
\hline Complications & No. of Patients & Percentage \\
\hline Nil & 48 & 96 \\
\hline $\begin{array}{c}\text { Airway } \\
\text { obstruction }\end{array}$ & 2 & 4 \\
\hline \multicolumn{3}{|c|}{ Table 3. Complications } \\
\hline
\end{tabular}

\begin{tabular}{|c|c|c|}
\hline Diagnosis & No. of Patients & Percentage \\
\hline Clinical & 14 & 28 \\
\hline Radiological & 36 & 72 \\
\hline \multicolumn{3}{|c|}{ Table 4. Diagnosis } \\
\hline \multicolumn{3}{|c|}{} \\
\hline
\end{tabular}

\begin{tabular}{|c|c|c|}
\hline Treatment & No. of Patients & Percentage \\
\hline I and D & 31 & 62 \\
\hline Needle aspiration & 9 & 18 \\
\hline $\begin{array}{c}\text { I and D and needle } \\
\text { aspiration }\end{array}$ & 5 & 10 \\
\hline Conservative & 5 & 10 \\
\hline \multicolumn{3}{|c|}{ Table 5. Treatment } \\
\hline
\end{tabular}

\section{DISCUSSION}

Deep neck space infections call for early diagnosis and prompt management. Morbidity in the deep neck space infections is mainly due to mediastinal complication.(3) The other complications which are rarely seen are jugular vein thrombosis, carotid artery rupture and meningitis.(4) The overwhelming complication rate of the past has been reduced with the advent of modern microbiology and haematology, the development of diagnostic tools like CT, MRI and by the effectiveness of modern antibiotics and the development of medical intensive care protocols and surgical techniques.(1)

The clinical picture depends on the spaces affected. They present with a wide range of symptomatology ranging from vague throat pain to severe respiratory embarrassment and dysphagia. Frequently accompanied by systemic toxicity and localised aerodigestive tract compromise and sometimes by life-threatening squeal like severe airway obstruction, mediastinitis, pericarditis, jugular vein thrombosis, epidural abscesses and carotid artery erosion. The treating surgeon should have a high index of suspicion in making the diagnosis of deep neck space infections. Clinical examination alone seems to underestimate the extent of disease in $70 \%$ of the cases, where appropriate radiological imaging can reveal infections spreading between the spaces.(5)

The microbiology of deep neck space infections usually reveals mixed aerobic and anaerobic organisms often with a predominance of oral flora. Both gram positive and gram negative organisms may be cultured. Group A beta haemolytic streptococci species, alpha haemolytic streptococcal species, staphylococcus aureus, fusobacterium nucleatum, bacteroides, peptostreptococci and Neisseria species are often found together in various combinations. ${ }^{(1)}$

The management protocols of these infections have not been well defined and are often challenging due to proximity to vital structures and its extension. Decision making between only medical management vs surgical and medical management are very important in dealing with the deep neck space infections. Surgical drainage is indicated as an early procedure in the presence of any suppurative infection of the neck.
In this study culture was negative in 15 cases (30\%), it may be because of improper use of antibiotics prior to presenting to our centre. Staphylococcus aureus (24\%) was the commonest organism isolated, followed by Beta haemolytic streptococci (16\%) and Alpha haemolytic streptococci (10\%); 2 (16.6\%) were Methicillin resistant (MRSA). MRSA should be considered as a potential pathogen in deep neck space abscesses. A high index of suspicion is needed as well as aggressive treatment including I and D along with culture directed medical therapy.

The increasing isolation of community acquired MRSA (CAMRSA) in head and neck abscesses has been a major focus of current literature. Studies by Ahmmed Shoukath et al revealed MRSA was the most common bacteria isolated and was seen in $50 \%$ of the culture positive patients and $40 \%$ of overall patients. Our data support the notion that MRSA infection are on the rise and due consideration should be given to it. Cultures are critical to determine the organism and its possible resistance patterns. Empirical antibiotics should cover gram positive especially MRSA, gram negatives and anaerobes. This study correlates with that of Ravi Meher studies, which shows culture negative in majority of their cases. Commonest organism isolated in their study is also staphylococcus aureus.(6)

Needle aspiration is the most commonly used treatment for peritonsillar abscess now as it is relatively pain free, less cumbersome procedure, not associated with any significant complications and is economical.(7) Majority of remaining cases were managed by incision and drainage, i.e. surgical management was preferred for medical management. In this study, early surgical intervention was the mainstay of treatment.

Ravi Meher in their studies recommended early incision and drainage as the standard treatment of choice for all deep neck infections.

In the study by DS Sethi $19 \%$ of patients developed complications, 6 developed necrotising cervical fasciitis. One had aspiration pneumonia, two developed acute myocardial infarction, four patients developed septicaemia and multiorgan failure. Mortality rate was 8.(2) In this study, 2 patients developed airway obstruction and underwent emergency tracheostomy and treated aggressively with broad-spectrum antibiotics under intensive care unit and survived. There was no mortality. Securing and maintaining an adequate airway must be the first priority.

Appropriate radiologic imaging can reveal infection spreading between spaces, which may not be clinically apparent. Contrast enhanced CT is currently considered the radiologic investigation of choice in deep neck infections.

In cases where parapharyngeal and retropharyngeal abscesses are suspected, CECT not only helps in diagnosis but also helps in identifying impending airway complications before they are clinically detectable, thereby reducing the complications.

Miller et al have concluded in their study that CECT has a high sensitivity and low specificity, which may lead to needless surgery for some patients if used in isolation. Clinical examination and CECT together are the most accurate test to determine the extent of Deep neck infection. ${ }^{(8)}$ 


\section{CONCLUSION}

Despite the widespread use of antibiotics, deep neck space infections continue to occur and causes great morbidity to the patient. Early presentation of the patients to the hospital has led to a decrease in the morbidity and mortality. CECT is essential in appropriate management of deep neck infections, especially in those involving parapharyngeal and retropharyngeal spaces.

Securing and maintaining an adequate airway must be the first priority. Endotracheal intubation or tracheostomy is done as per the requirement of the case.

Staphylococcus aureus (24\%) was the commonest organism isolated, followed by Beta haemolytic streptococci $(16 \%)$ and Alpha haemolytic streptococci (10\%). Polymicrobial infections were diagnosed in 2 cases (4\%). Out of 12 cases of Staphylococcus aureus, 2 (16.6\%) were Methicillin resistant (MRSA). MRSA should be considered as a potential pathogen in deep neck space abscesses.

A high index of suspicion is needed as well as aggressive treatment including incision and drainage along with culturedirected medical therapy.

Antibiotic coverage should include gram negative, gram positive and anaerobic micro-organisms. A combination of third generation cephalosporins and metronidazole are good as empiric antibiotic coverage. MRSA shows resistance to most of the cephalosporins and routine antibiotics, while it responds well to Vancomycin and Linezolid. Our data support the notion that MRSA infection are on the rise and due consideration should be given to it.

The complications of deep neck infection although less common now are still present and are higher in those with diabetes and immunocompromised states requiring aggressive management. Complications include mediastinitis, necrotising cervical fasciitis, septicaemia, multi-organ failure and airway obstruction.

\section{REFERENCES}

[1] Marioni G, Staffieri A, Parisi S, et al. Rational diagnostic and therapeutic management of deep neck infections: analysis of 233 consecutive cases. Ann Otol Rhinol Laryngol 2010;119(3):181-7.

[2] Scott BA, Stienberg CM, Driscoll BP. Deep neck space infections. $2^{\text {nd }}$ edn. In: Bailey BJ, Pillsbury HC, Brain P, et al. Head and neck surgery-otolaryngology. LippincottRaven, 1998:819-35.

[3] Kamath PM, Shetty AB, Hedge MC, et al. Presentation and management of deep neck space abscess. Indian J Otolaryngol Head Neck Surg 2003;55(4):270-5.

[4] Gidley PW, Ghorayeb BY, Steinberg CM. Contemporary management of deep neck space infections. Otolaryngol Head Neck Surg 1997;116(1):16-22.

[5] Sethi DS, Stanley RE. Deep neck abscesses--changing trends. J Laryngol Otol 1994;108(2):138-43.

[6] Parhiscar A, Har-El G. Deep neck abscess: a retrospective review of 210 cases. Ann Otol Rhinol Laryngol 2001;110(11):1051-4.

[7] Otasowie D, Benjamin I, Corneliu A. Management of neck space infections retrospective study of 70 patients. Niger Med Journal 2012;53:12-5.

[8] Nagy M, Backstrom J. Comparison of the sensitivity of lateral neck radiographs and computed tomography scanning in paediatric deep-neck infections. Laryngoscope 1999;109(5):775-9. 